\title{
CORPORATE SUSTAINABILITY PERFORMANCE: METHODS AND ILLUSTRATIVE EXAMPLES
}

\author{
R.J. BAUMGARTNER \\ Department of Economics and Business Management, University of Leoben, Austria.
}

\section{ABSTRACT}

The concept of sustainable development is of increasing importance for societies. Corporations are as relevant societal actors in an essential role for the realization and implementation of sustainable development. Therefore, it is necessary to assess the performance of corporations in the light of sustainable development. In this paper, basic methods and instruments for the assessment of corporate sustainability performance are compared. Sustainability assessments can be divided into two groups: The first group consists of methods based on monetary units; the second group consists of methods based on non-monetary units. The methods of Sustainable Value Added, Composite Sustainable Development Index and Integrated Sustainability Assessment are discussed in detail and evaluated regarding the criteria applicability, contribution to basic goals of sustainable development and completeness. The methods are used to assess the sustainability performance of BP and Royal Dutch/Shell Group.

Keywords: assessment, Composite Sustainable Development Index, corporate sustainability assessment, Integrated Sustainability Assessment, monetarization, sustainable business management, sustainable development, Sustainable Value Added.

\section{INTRODUCTION}

Assessing the sustainability performance of corporations is an important aspect within the transition of societies towards the principles of sustainable development. In this paper, three methods (Sustainable Value Added, Composite Sustainable Development Index, Integrated Sustainability Assessment) are presented. Sustainable Value Added is based on monetary units and assesses the value a company creates by using resources compared to a benchmark. Composite Sustainable Development Index and Integrated Sustainability Assessment are based on non-monetary units. These methods use different indicators for each dimension of sustainable development and combine them either with benefit analysis or with fuzzy logic. Depending on the goals used for the benchmark, relative and absolute contributions to sustainable development can be assessed.

The objective of sustainable development [1] is sustainability, which can be characterized by four principles. First, contribution to systematic increase in concentrations of substances from the earth's crust has to be eliminated. This means substituting certain minerals that are scarce in nature with others that are more abundant, using all mined materials efficiently, and systematically reducing dependence on fossil fuels. Second, contribution to systematic increases in concentrations of substances produced by society has to be eliminated. This means systematically substituting certain persistent and unnatural compounds with ones that are normally abundant or break down more easily in nature, and using these ones in an efficient and effective way. Third, contribution to the systematic physical degradation of nature through over-harvesting, introductions and other forms of modification has to be eliminated. This means drawing resources only from well-managed eco-systems, systematically pursuing the most productive and efficient use both of those resources and land, and exercising caution in all kinds of modification of nature. Fourth, contribute as much as possible to the meeting of human needs in our society and worldwide, over and above all measures taken in meeting the first three objectives. This means drawing resources only from well-managed eco-systems, systematically pursuing the most productive and efficient use both of those resources 
and land, and exercising caution in all kinds of modification of nature [2]. This means for the economic development - as means to an end to reach the first three principles - to generate wealth, especially for poorer people, in ways that are compatible with these principles ([3], p. 77). Sustainability calls for an economic system that meets the needs of people, provides enough jobs and is able to rejuvenate itself to provide these services in the long run ([4], p. 30).

These four principles are the framework for all societal and corporate activities toward sustainable development. To meet these principles two general mechanisms - dematerialization and substitution can be used. Dematerialization deals either with resource productivity or reduction of waste. Substitution differs from principle to principle. For the first and second principle, substitution means using more abundant materials from the earth's crust or compounds that are occurring naturally. For the third principle, the substitution of certain activities, which are identified as nature destructing, is the task. And the fourth principle includes health aspects through ecological pollution, availability and distribution of resources [2].

\section{ASSESSMENT OF CORPORATE SUSTAINABILITY PERFORMANCE}

Business sustainability can be defined as "adopting business strategies and activities that meet the needs of the enterprise and its stakeholders today while protecting, sustaining and enhancing the human and natural resources that will be needed in the future" [5]. Roome defines the term sustainable business management as "management of business that recognizes its embeddedness in social, environmental and economic systems, and focuses on management and relationships to meet the environmental, social, and economic requirements of many different stakeholders in its networks" [6]. Both definitions show the importance of stakeholders and the broader view of business, which is embedded in society and nature. Additionally, it is essential to regard the basic principles of sustainable development described in Section 1.

Assessing the corporate sustainability performance means to answer the question whether the company contributes to the intention and principles of sustainable development. Bennet and James define sustainability performance measurement and management as the measurement and management of the interaction between business, society and the environment [7]. This definition highlights the embeddedness of a company in the economic, societal and environmental system. It is essential to measure the impact the interactions have on other systems. In business practice and science, there is no consensus about sustainability performance measurement and assessment methods.

These methods are based on either monetary units or non-monetary units. The former evaluates corporate sustainability performance with costs and benefits due to corporate activities. The crucial step is the monetarization of environmental and social impacts which is difficult and still controversially discussed ([8], p. 43; [9]; [10], p. 155; [11], p. 175). The latter does not require any translation of environmental and social impacts into monetary units. Additionally, there are absolute and relative measures used. In case of absolute measures, the company contributes to sustainability if the benefits exceed the sum of internal and external costs in case of a monetary assessment ([11], p. 175) or if the non-monetary measures show a positive contribution to sustainability, which requires the knowledge of a sustainable threshold level. Relative measures express corporate contributions to sustainability as benefits per unit of environmental or social impact. One example for a relative measure is eco-efficiency [12]. The ratio of the sustainability performance of the company compared to a benchmark is a relative measure, too. Relative measures do not give any information about effectiveness as efficiency gives information about the relation between two aspects and can be expressed with monetary or non-monetary units or a combination of them.

The methods presented in this paper are either widely used in practice or highlight important aspects of corporate sustainability assessment. 


\subsection{Sustainable Value Added}

Sustainable Value Added was developed by Figge and Hahn [11, 13]. This method is a relative measure based on monetary units. The basic idea is to answer the question where resources have to be allocated to achieve the highest contribution to sustainability. It is based on opportunity costs and shows how much more value is created because a company is more efficient than a benchmark and because the resources are allocated to the company and not to a benchmark. According to Figge and Hahn, in the context of corporate contributions to sustainability, the most obvious question to answer is whether a company has contributed to the sustainability of a national economy during the period of time under observation; therefore, the national economy should be used as benchmark ([11], p. 179).

Due to the introduction of opportunity costs Sustainable Value Added posits on compensation instead of substitution: this means potential sources of externalities are compensated for the avoidance of externalities with opportunity costs and the sum of capital is kept constant, which refers to the paradigm of strong sustainability (for weak and strong sustainability, see [14]). This method shows that if there are enough funds available to pay others to reduce their impacts, it obviously does not give any information on the willingness to spend theses funds or if there is a market or trading scheme which would be needed to really pay the compensations ([11], p. 183). For cases where resource flows have to be steadily reduced to achieve constant stocks of critical capital, resource specific reduction factors can be introduced ([11], p. 183), but such reduction factors have not been published yet. Figge and Hahn also discuss to introduce external costs in their method to identify the price of weak over strong sustainability.

With this method, the relative corporate contribution to sustainability can be measured in absolute monetary terms. It does not show whether the use of the resource by this entity is sustainable in absolute terms, but it indicates how much more sustainable (in monetary terms) the use of the resource is in comparison with other entities ([11], p. 177). The sustainable value is calculated in five steps ([15], p. 18):

1. How much of a resource does a company use?

The first step determines the amount of resources the company uses during the year. In principle economic, environmental and social resources can be considered; social resources are considered negative social impacts (e.g., work accidents). The (physical) data on the use of different resources represent the starting point for the calculation. The selection of the resources included in the calculation of Sustainable Value Added has to be made according to the goal of the assessment.

2. How much return does the company create with these resources?

In this step, the return the company creates with these resources is measured. It can be measured with gross value added ([15], p. 19), which is the return that is created for shareholders and creditors, the government/state and the personnel; it represents a company's contribution to gross domestic product (GDP). Alternatively, the return the company creates with these resources can be calculated with net value added [16]. By dividing the gross value added/net value added with the amount of a resource used by the company the resource efficiency can be calculated.

3. How much return would the benchmark create with these resources?

This step determines how much return would be created, if the resources were used not by the company but by the benchmark. Each resource can be used only once. Therefore, one cannot benefit from both, the return the company creates and the return the benchmark would create. 
As the company uses the resources, the return the benchmark would create is foregone. The foregone return is equivalent to opportunity cost.

The benchmark regarded for the calculation has to be defined. Depending on the goal of the assessment, the benchmark can be the national economy ([11], p. 179) or the average of an industrial sector [17]. To be able to compare the return created by the company with the return created by the benchmark, the return figure used on the benchmark level must correspond to the return figure used for the company. On the company level, gross value added is used; this return figure corresponds to the GDP on the benchmark level.

4. Which resources are used in a value-creating way by the company and which are not?

The return the company creates with each resource is compared with the return created by the benchmark. The return the company creates corresponds to its gross value added/net value added, the return of the benchmark are the opportunity costs. The value contribution is calculated by subtracting the opportunity costs of each resource from the gross value added/net value added. It shows how much more or less value a company creates with a resource compared to the benchmark.

5. How much sustainable value does the company create?

In the step before, the value contribution of an individual resource was calculated. As every company uses more than one resource, these individual value contributions have to be combined. The sustainable value is calculated by dividing the sum of the value contributions by the number of resources considered. Simply summing up the value contributions would result in double counting as the bundle of used resources creates the value; through this aggregation, the resources are weighted relative to their efficiency on the benchmark level.

The absolute level of Sustainable Value Added depends beside other factors on the company size. To enable comparison of different companies, the company size has to be taken into account. Figge and Hahn suggest the sustainable value margin and the return to cost ratio for this. The former is calculated by dividing the sustainable value by sales; it reflects how much sustainable value is created by $1 €$ of sales the company makes. The latter is calculated by dividing the gross value added created by the company to the opportunity costs it causes and is therefore a benefit-cost ratio; it reflects by which factor the gross value added of the company exceeds the opportunity costs and vice versa ([15], p. 23).

\subsection{Composite Sustainable Development Index}

This method was presented by Krajnc and Glavic $[18,19]$. It is based on non-monetary units and delivers an index representing the sustainability performance. Depending on the definition of the used indicators, absolute and relative corporate contributions to sustainable development can be assessed. The model reduces the number of indicators by aggregating them into a Composite Sustainable Development Index $\left(I_{\mathrm{CSD}} ; 0 \leq I_{\mathrm{CSD}} \leq 1\right)$. The index consists of an economic sub-index $\left(I_{\mathrm{S}, 1}\right)$, an environmental sub-index $\left(I_{\mathrm{S}, 2}\right)$ and a social sub-index $\left(I_{\mathrm{S}, 3}\right)$. The sub-indices are built of normalized indicators.

The procedure for calculating the index is divided into several parts $[18,19]$.

\section{Selection, grouping and judging the indicators}

First, proper performance indicators are selected covering different aspects of sustainability. Then the indicators are grouped into the three dimensions of sustainable development. The economic group of indicators concerns the impact of the company on the economic well being 
of its stakeholders and on economic systems. The environmental group of indicators covers the impact of the company on the ecosphere. The societal group of indicators reflects the impact of the company on its stakeholders and the society. Additionally, it is regarded whether an increased value of an indicator has a positive or negative impact on sustainability performance. For example, increased value of air emissions per unit of production has a negative impact; this indicator is of type "less is better."

Examples for indicators are sales, operating profit, investment capital/investment expenditures, net earnings, $R \& D$ costs or number of employees for the economic dimension, total energy consumption, production mass, emissions $\left(\mathrm{CO}_{2}, \mathrm{NO}_{x}, \mathrm{SO}_{2}\right.$, dust, etc.), wastewater or waste for the environmental dimension and number of work accidents, number of complaints due to any kind of exposition or number of improvement measures for the social dimension [18].

2. Weighting

Pair-wise comparison technique is used to derive relative weights of each indicator. This method is based on the analytic hierarchy process (AHP) [20]. First, the problem has to be set as a hierarchy where the topmost node is the overall objective of the decision, while subsequent nodes at lower levels consist of the criteria used in arriving at this decision. The second step requires the pair-wise comparisons to be made between each pair of indicators of the given level of hierarchy. The comparisons are made by posing the question which of the two indicators $i$ and $j$ is more important with respect to the sustainability performance of the company. The intensity of preference is expressed on a factor scale from 1 to 9 , the value of 1 indicates equality between the two indicators while a preference of 9 indicates that one indicator is nine times the importance of the one to which it is being compared. These pair-wise comparisons result in a $(N \times N)$ positive reciprocal matrix $\mathbf{A}$, where the diagonal $a_{i j}=1$ and the reciprocal property $a_{j i}=\left(1 / a_{i j}\right), i, j=1, \ldots, n$ assuming: if indicator $i$ is " $p$ times" the importance of indicator $j$, then indicator $j$ is " $1 / p$ times" the importance of indicator $i$. The process of comparison is repeated for each column of the matrix, making independentjudgments overeach pair of indicators. At the end, matrix $\mathbf{A}$ is filled with the relative weights. To find the normalized weight of each indicator, each column in matrix $\mathbf{A}$ is normalized (by dividing an indicator relative weight by the sum of the relative weights in column); then the values across the rows are averaged which leads to the normalized weight vector $\mathbf{W}$ containing weights $\left(W_{j i}\right)$ of sustainability indicators selected. The quality of this judgment process can be regarded with the consistency ratio $R_{\mathrm{c}}$ ([18], p. 195). Critical in this process is the selection of the persons who make the judgments.

3. Normalizing

Indicators used for the composite sustainable development index are expressed in different units. Therefore, they have to be normalized. Krajnc and Glavic suggest two methods for normalization [18]. The first possibility is to divide the value in time of an indicator with its target value determined by realistic assessment of unexploited potentials for the company. The second possibility is to normalize the indicator dividing the difference between actual and minimum level with the difference between maximum and minimum level of this indicator (for indicators of type "more is better") respectively to subtract the result of this division from 1 for indicators of the type "less is better" (see Fig. 1). By this normalization, it is possible to incorporate different kinds of quantities with different units of measurement. As all indicators are normalized, different indicators are compatible and comparable.

Assessing absolute corporate contributions to sustainable development requires target values derived from sustainable threshold levels (describing critical capital stocks or critical mass flows). 


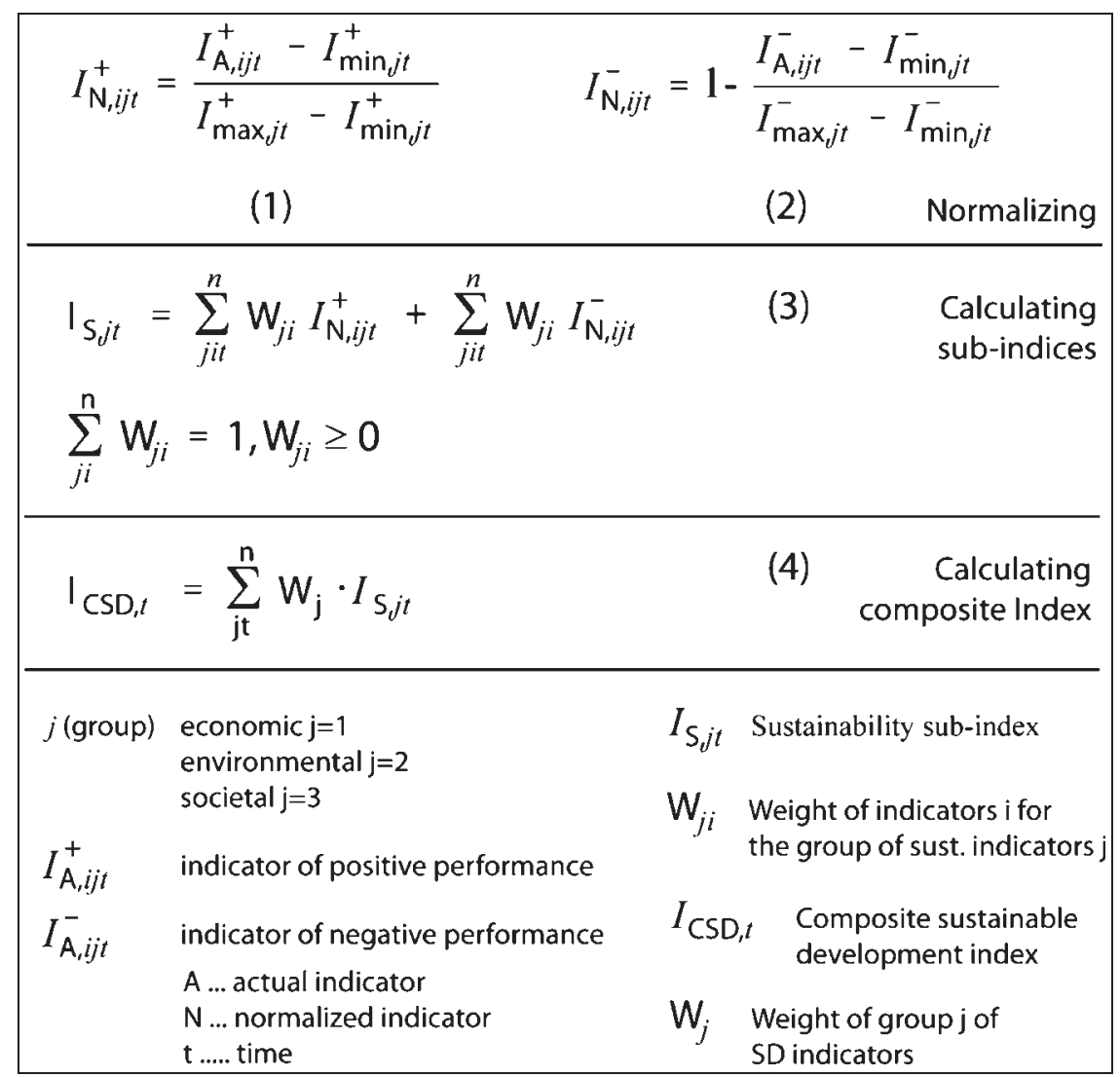

Figure 1: Formula for Composite Sustainable Development Index [19].

4. Calculating sub-indices and combining to composite sustainable development index

The sub-indices are calculated by multiplying each normalized indicator value with its weight and summing up all multiplications (benefit analysis). Accordingly, the composite index is calculated by multiplying each sub-index with its weight and summing up the three results for the sub-indices. The weight of each sustainability dimension can be obtained with AHP, too, or be estimated; the weightshouldreflecttheimportancegiventotheeconomic, environmentalandsocialperformance of the company. A requirement for this calculation is independence of the criteria: the sustainability dimension and the indicators describing each sustainability dimension have to be independent for a mathematically correct benefit analysis ([21], p. 39; [22]). In reality, this requirement maybe difficult to fulfill.

\subsection{Integrated Sustainability Assessment}

Baumgartner introduced Integrated Sustainability Assessment for the assessment of products, services and technologies [22, 23]. This method can be used for assessing the sustainability performance of a company, too. The central element is the combined assessment - based on fuzzy logic [24] - of the environmental, economic and social dimension of sustainable development. Fuzzy logic enables 
specific weighting of social, economic and ecological aspects and translates blurred input signals into stable global results. Fuzzy logic can combine indicators that are measured in different units (normalization not required) and indicators, which are not independent. The structure of a fuzzybased scoring model consists of the steps defining logical composition rules, fuzzification, inference and defuzzification ([23]; [25], p. 69).

1. Defining logical composition rules

The logical composition rules are defined as If-then conclusions. These rules consist of a condition and a consequence part. An example of a rule could be as follows: "If the improvement of environmental performance is small and the creation of value is strongly worsened then the total evaluation is worse." The condition part consists of "If the improvement of environmental performance is small and the creation of value is strongly worsened," and the consequence part consists of "then the total evaluation is worse."

In the condition section several premises (here "environmental performance" and "creation of value") can be combined with the help of logical relations. Premises and consequences are linguistic variables; the terms (values) of the variables are words or sentences. Each term is defined by a membership function $\mu(0 \leq \mu \leq 1)$, which can have triangular, trapezoidal or bell-type shapes ([26], p. 44). In our case, triangular membership functions are used. For an illustrative example, see Fig. 2.

2. Fuzzification

The membership functions of the terms of the linguistic variable have to be determined, which is called fuzzification. This is illustrated with Fig. 2: a person with age 40 belongs with $\mu=0.6$ to the term "middle age" and with $\mu=0.4$ to the term "young" of the linguistic variable "age."

3. Inference

In this step, conclusions from the premises to the consequences have to be made. For instance, a rule is defined as follows: "If the improvement of the environmental performance is small and

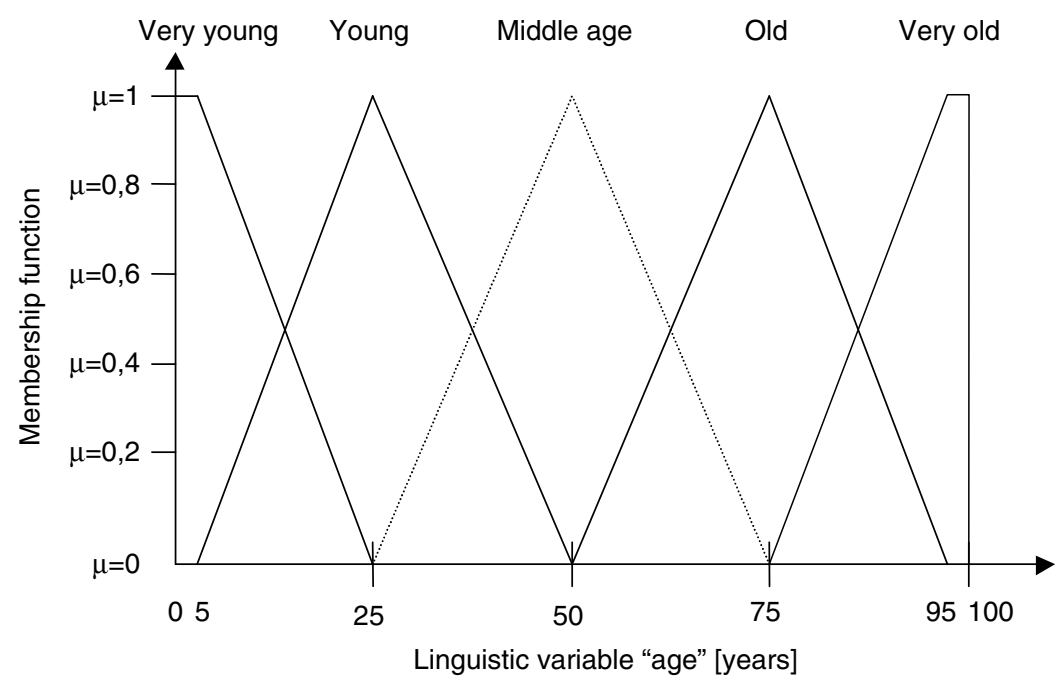

Figure 2: Linguistic variable age [23], based on [26]. 
the creation of value is strongly worsened then the total evaluation is worse." The variables environmental performance and creation of value consist of the terms small, identical and better, the variable total evaluation of the terms unacceptable, acceptable and excellent. The membership function for environmental performance (small) is $\mu=0.3$ and for value creation (small) is $\mu=0.7$, the inference defines the membership function for total evaluation (unacceptable). The results depend on the logical operator used in the condition part. Basis operators are "and," which represents a minimum operator, and "or," which is a maximum operator. In our example, "and" is used, therefore the conclusion is defined with $\mu=0.3$ ([27], p. 123).

4. Defuzzification

As result, a sharp value of the membership functions of the conclusions is calculated. Therefore, different methods exist - a simple, but sufficient represents the so-called Singleton procedure ([27], p. 124).

With Integrated Sustainability Assessment, different indicators measuring sustainability aspects can be combined. They can be quantitative and qualitative and be measured at least on an ordinal scale. Monetarization of environmental and social impacts is not necessary.

\section{APPLICATION AND EVALUATION: THE EXAMPLE OF BP AND ROYAL DUTCH/SHELL}

The application of the methods Sustainable Value Added, Composite Sustainable Development Index and Integrated Sustainability Assessment is demonstrated in the example of BP and Royal Dutch/Shell for the year 2003 using data of Figge [15] and Krajnc and Glavic [19]. Each method is evaluated regarding the criteria applicability, contribution to the goals of sustainable development and completeness.

\subsection{Sustainable Value Added}

\subsubsection{Example}

This example is taken from the advance project, a research project funded by the EU and participating organizations [15]. ADVANCE applies the Sustainable Value approach to assess the use of seven environmental resources by 65 European companies from 16 countries and 18 different sectors. The considered environmental resources are carbon dioxide $\left(\mathrm{CO}_{2}\right)$ emissions, nitrogen oxide $\left(\mathrm{NO}_{x}\right)$ emissions, sulfur oxide $\left(\mathrm{SO}_{x}\right)$ emissions, emissions of volatile organic compounds (VOC), methane $\left(\mathrm{CH}_{4}\right)$ emissions, waste generation and water use. In this case, the social dimension is not considered. The benchmark consists of the eco-efficiency of the EU15 countries (member states before enlargement in 2003). The size of the companies is taken with the return to cost ratio into account. It relates the gross value added created by the company to the opportunity costs it causes and is therefore a typical benefit-cost ratio. If the return to cost ratio is smaller than 1, the company uses its set of resources less efficiently than the benchmark. In this case, the company destroys sustainable value ([15], p. 23).

The efficiency of the EU15-benchmark in 2003 is for $\mathrm{CO}_{2} 2,701 € / \mathrm{t}, \mathrm{NO}_{\mathrm{x}} 1,004,300 € / \mathrm{t}$, $\mathrm{SO}_{x} 1,779,300 € / \mathrm{t}$, Waste $6,270 € / \mathrm{t}$, Water $41 € / \mathrm{t}$, VOC $970,676 € / \mathrm{t}$ and $\mathrm{CH}_{4} 586,083 € / \mathrm{t}$ [15].

The results show for Royal Dutch/Shell Group a sustainable value of $-180,917,018,746 €$. BP Group reached a sustainable value of $-134,132,952,397 €$. Both companies are producing less value than the benchmark and are destroying sustainable value. Their business is relatively unsustainable compared to the eco-efficiency of the EU15. BP shows better results, mainly due to lower emissions of $\mathrm{SO}_{x}$ and waste (see Table 1). 
Table 1: Sustainable value of Royal Dutch/Shell and BP ([15], pp. 98, 139).

\begin{tabular}{|c|c|c|}
\hline 2003 & Shell Group & BP Group \\
\hline \multicolumn{3}{|l|}{ Performance } \\
\hline Gross value added (€) & $37,102,687,000$ & $30,651,662,600$ \\
\hline Sales $(€)$ & $238,076,976,800$ & $205,918,363,400$ \\
\hline $\mathrm{CO}_{2}$-emissions ( $\mathrm{t}$ ) & $106,000,000$ & $88,890,000$ \\
\hline $\mathrm{NO}_{x}$-emissions (t) & 220,000 & 220,318 \\
\hline $\mathrm{SO}_{x}$-emissions (t) & 292,000 & 150,895 \\
\hline Waste (t) & $1,064,000$ & 526,749 \\
\hline Water used $\left(\mathrm{m}^{3}\right)$ & $1,690,000,000$ & $516,922,761$ \\
\hline VOC-emissions (t) & 294,000 & 268,785 \\
\hline $\mathrm{CH}_{4}$-emissions $(\mathrm{t})$ & 234,000 & 235,400 \\
\hline \multicolumn{3}{|c|}{ Opportunity costs of resource use by the company } \\
\hline $\mathrm{CO}_{2}$-emissions $(€)$ & $286,352,338,596$ & $240,130,748,847$ \\
\hline $\mathrm{NO}_{x}$-emissions $(€)$ & $220,945,957,291$ & $221,265,324,629$ \\
\hline $\mathrm{SO}_{x}$-emissions $(€)$ & $519,556,661,315$ & $268,488,021,949$ \\
\hline Waste $(€)$ & $6,671,127,687$ & $3,303,640,825$ \\
\hline Water used $(€)$ & $70,089,609,574$ & $21,438,410,946$ \\
\hline VOC-emissions (€) & $285,378,845,537$ & $260,903,241,488$ \\
\hline $\mathrm{CH}_{4}$-emissions $(€)$ & $137,143,400,225$ & $137,963,916,295$ \\
\hline \multicolumn{3}{|l|}{ Value contributions } \\
\hline $\mathrm{CO}_{2}$-emissions $(€)$ & $-249,249,651,596$ & $-209,479,086,247$ \\
\hline $\mathrm{NO}_{x}^{-}$-emissions $(€)$ & $-183,843,270,291$ & $-190,613,662,029$ \\
\hline $\mathrm{SO}_{x}$-emissions $(€)$ & $-482,453,974,315$ & $-237,836,359,349$ \\
\hline Waste $(€)$ & $30,431,559,313$ & $27,349,021,775$ \\
\hline Water used $(€)$ & $-32,986,922,574$ & $9,213,251,654$ \\
\hline VOC-emissions (€) & $-248,276,158,537$ & $-230,251,578,888$ \\
\hline $\mathrm{CH}_{4}$-emissions $(€)$ & $-100,40,713,225$ & $-107,312,253,695$ \\
\hline Sustainable value & $-180,917,018,746$ & $-134,132,952,397$ \\
\hline Rank & 49 & 47 \\
\hline Return to cost ratio & $1: 5.9$ & $1: 5.4$ \\
\hline
\end{tabular}

3.1.2 Evaluation

This method is based on data that are published in annual reports and sustainability reports. Data from annual reports are usually reliable due to external auditing. Data from sustainability reports are not in every case reliable, external auditing is not obligatory. The methodology is well described and not complicated in its application. The method assesses the relative contribution to sustainable development and absolute levels of sustainability cannot be assessed. Regarding completeness only environmental resources are assessed, but social impacts can also be assessed if a return and a benchmark can be identified, as Hahn et al. show in another example [17]. 
As Sustainable Value Added is a relative measure, it can help answer an allocative question: which company can use the regarded resources most efficient? According to ([11], p. 178) with Sustainable Value Added an absolute amount of capital cannot be identified - companies can produce a positive sustainable value, but the sum of all companies can have an impact on an unsustainable level. Additionally, only these resources and impacts can be included where a return and opportunity costs can be calculated.

\subsection{Composite Sustainable Development Index}

\subsubsection{Example}

This example was published by Krajnc and Glavic [19]. It shows the application of the Composite Sustainable Development Index on Royal Dutch/Shell and BP Group. Table 2 shows the values for the year 2003, the normalized values are derived from values for the years 2000-2003. Tables 2 and 3 present the results. In this example, the social and the economic dimension are assessed, too.

The assessment with this method delivers the same result that BP is performing better than Shell. BP performs in the economic and environmental dimension better than Shell, which shows a better performance in the social dimension.

\subsubsection{Evaluation}

This method is well described; data needed for application are available in annual reports and sustainability reports. This method needs higher effort to identify the criteria and to determine the relative weights of the dimensions and the criteria. Regarding sustainable development, relative and absolute levels can be assessed, depending on the benchmark level used for the assessment. This method allows a complete assessment and all dimensions of sustainable development can be regarded. A disadvantage of this method is the methodological restrictions of benefit analysis: each criterion has to be independent and all values have to be normalized to a similar scale. As this example shows, the independence of criteria cannot be guaranteed.

\subsection{Integrated Sustainability Assessment}

\subsubsection{Example}

For this example, data from Krajnc and Glavic [19] are used. The assessment is relative, which means that the Shell Group is assessed relative to the BP Group. The criteria $\mathrm{CO}_{2}, \mathrm{NO}_{x}, \mathrm{CH}_{4}, \mathrm{SO}_{2}$ and hazardous wastes are used for the environmental dimension, cash flow is used for the economic dimension and fraction of societal and community investment in gross profit and recordable injury frequency for employees and contractors (all values see Table 2) are used for the social dimension. Each criterion is defined as linguistic variable with the linguistic terms "better," "identical" and "worse" on a scale from 0 to 100 points; triangular membership functions are used. Each criterion is assessed relatively, which means that the ratio from the values for Shell against BP is calculated. This ratio is normalized and used as input for the linguistic variables. 100 points correspond to an increase of $50 \%$ of positive indicators (like cash flow) respectively to a decrease of $50 \%$ of negative indicators (like emissions). This normalization is not necessary due to methodological reasons; it just simplifies the calculation. With a fuzzy-system, it is not necessary to use the same scale for each criterion for the transformation into linguistic variable, so transformation in linguistic variable can be made individual for each criterion. Additionally, the criteria do not have to be independent.

The assessment consists of the steps defining indicators, calculation of the Shell/BP ratio and normalization, environmental assessment (including rules), social assessment (including rules), 
Table 2: Indicators, weights, values and normalized values [19].

\begin{tabular}{|c|c|c|c|c|c|c|}
\hline \multirow[b]{2}{*}{ Indicator } & \multirow[b]{2}{*}{ Weight } & \multirow[b]{2}{*}{ Unit } & \multicolumn{2}{|c|}{ Shell Group } & \multicolumn{2}{|c|}{ BP Group } \\
\hline & & & & Normalized & & Normalized \\
\hline \multicolumn{7}{|l|}{ Economic } \\
\hline $\begin{array}{l}\text { Cash flow after taxation relative } \\
\text { to unit of production } \\
\text { (UP, mass of oil equivalents) }\end{array}$ & 0.120 & $\mathrm{USD} / \mathrm{t}$ & 64 & 0.80 & 58 & 0.62 \\
\hline $\begin{array}{l}\text { Fraction of R\&D expenditure } \\
\text { in gross profit }\end{array}$ & 0.281 & $\%$ & 1.7 & 0.97 & 1.2 & 0.00 \\
\hline Exploration cost relative to UP & 0.363 & $\mathrm{USD} / \mathrm{t}$ & 7.59 & 0.00 & 3.02 & 0.96 \\
\hline $\begin{array}{l}\text { Environmental and safety } \\
\text { fines and penalties cost }\end{array}$ & 0.236 & MUSD & 17 & 0.42 & 7 & 0.79 \\
\hline \multicolumn{7}{|l|}{ Environmental } \\
\hline $\begin{array}{l}\text { Mass ratio of } \mathrm{CO}_{2} \text { emissions } \\
\text { to UP }\end{array}$ & 0.061 & $\mathrm{~kg} / \mathrm{t}$ & 545.12 & 0 & 437.17 & 0.86 \\
\hline $\begin{array}{l}\text { Mass ratio of } \mathrm{CH}_{4} \text { emissions } \\
\text { to UP }\end{array}$ & 0.055 & $\mathrm{~kg} / \mathrm{t}$ & 1.20 & 0.03 & 1.34 & 1.00 \\
\hline $\begin{array}{l}\text { Mass ratio of } \mathrm{SO}_{2} \text { emissions } \\
\text { to UP }\end{array}$ & 0.110 & $\mathrm{~kg} / \mathrm{t}$ & 1.50 & 0.89 & 0.84 & 0.70 \\
\hline $\begin{array}{l}\text { Mass ratio of } \mathrm{NO}_{x} \text { emissions } \\
\text { to UP }\end{array}$ & 0.103 & $\mathrm{~kg} / \mathrm{t}$ & 1.13 & 0.00 & 1.23 & 0.82 \\
\hline $\begin{array}{l}\text { Mass ratio of hazardous waste } \\
\text { to UP }\end{array}$ & 0.263 & $\mathrm{~kg} / \mathrm{t}$ & 2.85 & 0.78 & 1.33 & 0.98 \\
\hline $\begin{array}{l}\text { Mass ratio of spills to UP } \\
\text { Societal }\end{array}$ & 0.407 & $\mathrm{~kg} / \mathrm{t}$ & 0.03 & 0.08 & 0.02 & 0.49 \\
\hline $\begin{array}{l}\text { Fraction of societal and } \\
\text { community investment } \\
\text { in gross profit }\end{array}$ & 0.0692 & $\%$ & 0.30 & 0.33 & 0.25 & 0.00 \\
\hline $\begin{array}{l}\text { Number fraction of fatalities } \\
\text { per employee }\end{array}$ & 0.2744 & $\%$ & 0.0042 & 0.76 & 0.0048 & 0.67 \\
\hline $\begin{array}{l}\text { Fatality accident rate for } \\
\text { employees and contractors }\end{array}$ & 0.2410 & 1/100 Mh & 5.40 & 0.49 & 3.80 & 0.77 \\
\hline $\begin{array}{l}\text { Recordable injury frequency } \\
\text { for employees and contractors }\end{array}$ & 0.4154 & $1 / \mathrm{Mh}$ & 2.30 & 1.00 & 3.05 & 0.81 \\
\hline
\end{tabular}

Table 3: Composite Sustainable Development Index and sub-indices [19].

\begin{tabular}{lccc}
\hline Index & Weights & Shell Group & BP Group \\
\hline Economic sub-index $\left(I_{\mathrm{ECN}}\right)$ & 0.329 & 0.467 & 0.607 \\
Environmental sub-index $\left(I_{\mathrm{ENV}}\right)$ & 0.407 & 0.470 & 0.904 \\
Societal sub-index $\left(I_{\mathrm{SOC}}\right)$ & 0.264 & 0.784 & 0.700 \\
Composite Sustainable Development Index $\left(I_{\mathrm{CSD}}\right)$ & 1 & 0.552 & 0.753 \\
\hline
\end{tabular}




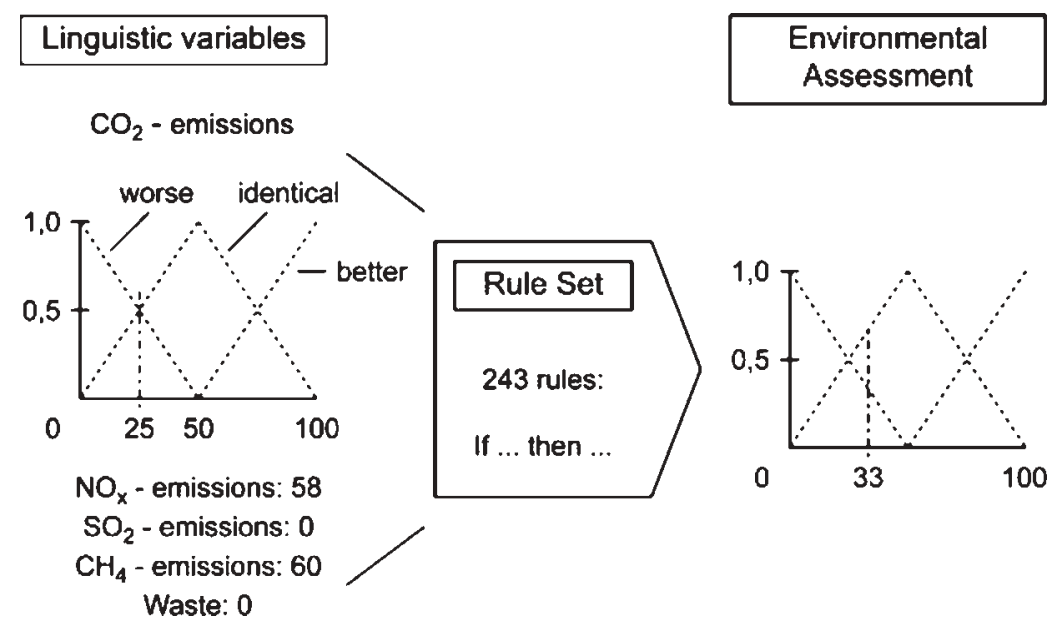

Figure 3: Environmental assessment.

economic assessment and integrated assessment. Because there is more than one indicator for the environmental and social dimension, they have to be combined in an environmental and social assessment. The results are expressed as linguistic variables environmental assessment and social assessment with the terms "better," "identical" and "worse" on a scale from 0 to 100 points with triangular membership functions.

For the environmental assessment, the indicators are transformed to linguistic variables. Figure 3 shows this for the criterion $\mathrm{CO}_{2}$ emissions: The normalized input value is 25 (the $\mathrm{BP} / \mathrm{Shell}$ ratio is 1.25); this means that the terms "worse" and "identical" are relevant. All linguistic variables are combined with 243 rules (five variables with three terms); these rules define the assessment and reflect the preferences of the assessor.

An example for a rule is: If $\mathrm{CO}_{2}$-emissions are "worse" and $\mathrm{NO}_{x}$-emissions are "better" and $\mathrm{SO}_{2}$-emissions are "worse" and $\mathrm{CH}_{4}$-emissions are "identical" and waste is "better" then environmental assessment is "identical." The assessment results in a defuzzified value of 33 (see Fig. 3). The indicators of the social dimension fraction of societal and community investment in gross profit with a normalized value of 64 and recordable injury frequency for employees and contractors with a normalized value of 75 are combined with nine rules in the social assessment. The defuzzified value for the social assessment is 75 .

For the general assessment, the social, environmental and economic assessments are combined with 27 rules. The economic dimension is measured with cash flow as the indicator; the normalized value of cash flow is 60 . The assessment results after defuzzification in 30 points on a scale from 0 to 100 points (see Fig. 4; a result of 50 points would correspond to an identical performance). This means that Shell is performing 20\% worse than BP Group does. The performance of Shell in the economic and social dimension is better, but worse in the environmental dimension where Shell has higher emissions of $\mathrm{CO}_{2}, \mathrm{SO}_{2}$ and waste.

\subsubsection{Evaluation}

This method allows a flexible assessment of corporate sustainability performance through an individual setting of the combining composition rules. Therefore, this method can be used for internal performance management and controlling processes. It can be used for an external assessment too; 


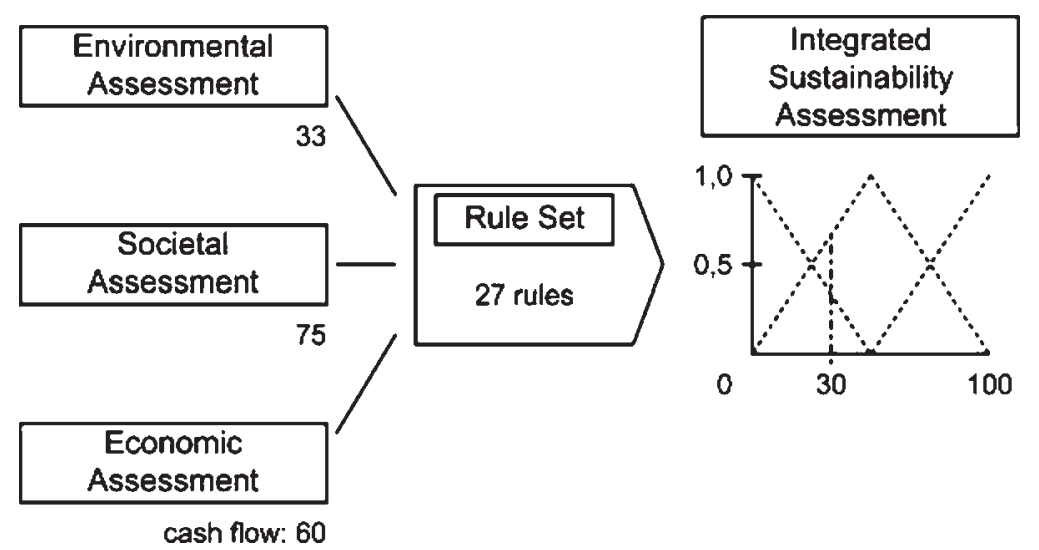

Figure 4: General assessment.

in this case, rules have to standardized, which is also necessary for the Composite Sustainable Development Index. Compared to this index, criteria used for the Integrated Sustainability Assessment do not have to be independent and the values of the criteria normalized; this increases the flexibility.

Regarding contribution to sustainable development, absolute and relative levels of sustainable development can be assessed depending on the used criteria and benchmark levels for the criteria. This method allows a complete assessment and all dimensions of sustainable development can be regarded.

\section{CONCLUSION}

In this paper, methods for the assessment of corporate sustainability performance are described and compared. All presented methods are practicable in the sense that they are able to assess corporate contributions to sustainable development. The methods are either based on monetary or on nonmonetary units. Sustainable value can assess relative contributions to sustainable development; the other methods can assess also absolute contributions to sustainable development, if absolute sustainability goals are used as benchmark. The results of the example Shell and BP show that all methods assess the performance of BP Group better than the performance of Royal Dutch/Shell. This indicates, for this example, that the selection of the assessment method does not influence the ranking.

In general, the selection of an assessment method has to be based on the goal of the assessment: is it carried out by the company itself and used for internal purposes like strategy planning and management or for external purposes like marketing or stakeholder information or is the assessment carried out by an external group? The example in Section 3 shows the weaknesses and strength of each methodology to allow the selection of the best method for each assessment situation.

\section{ACKNOWLEDGEMENTS}

The author thanks two anonymous referees for helpful suggestions and comments.

\section{REFERENCES}

[1] World Commission on Environment and Development, Our Common Future, Oxford University Press: Oxford, 1987.

[2] Robèrt, K.-H., Schmidt-Bleck, B., Aloisi de Laderel, J., et al., Strategic sustainable development - selection, design and synergies of applied tools. Journal of Cleaner Production, 10(3), pp. 197-214, 2002. 
[3] James, P., Towards sustainable business? Sustainable Solutions: Developing Products and Services for the Future, eds M. Charter \& U. Tischner, Greenleaf Publishing: Sheffield, 2001.

[4] Spangenberg, J.H., Sustainable development: from catchwork to benchmarks and operational concepts. Sustainable Solutions: Developing Products and Services for the Future, eds M. Charter \& U. Tischner, Greenleaf Publishing: Sheffield, 2001.

[5] Deloitte \& Touch/ISSD, Business Strategy for Sustainable Development: Leadership and Accountability for the '90s, IISD: Winnipeg, Canada, 1992.

[6] Roome, N.J. (ed.), Sustainable development and the industrial firm. Sustainable Strategies for Industry: The Future of Corporate Practice, Island Press: Washington, DC, 1998.

[7] Bennet, M., \& James, P., Environment-Related Performance Measurement: Current Practice and Trends, Ashridge Management College: Ashridge, 1997.

[8] Krotschek, C., Prozeßbewertung in der nachhaltigen Wirtschaft (Process Assessment in a Sustainable Economy), Technical University, Graz, 1995.

[9] Narodoslawsky, M., \& Krotschek, C., The Sustainable Process Index - a new dimension in ecological evaluation. Ecological Engineering, 6(4), pp. 241-258, 1996.

[10] Common, M. \& Stagl, S., Ecological Economics, Cambridge University Press: Cambridge, 2005.

[11] Figge, F. \& Hahn, T., Sustainable Value Added - measuring corporate contributions to sustainability beyond eco-efficiency. Ecological Economics, 48(2), pp. 173-187, 2004.

[12] Lehni, M., Eco-efficiency Indicators: A Tool for Better Decision-Making, World Business Council For Sustainable Development (WBCSD): Geneva, 1999.

[13] Figge, F. \& Hahn, T., The cost of sustainability capital and the creation of sustainable value by companies. Journal of Industrial Ecology, 9(4), pp. 47-58, 2005.

[14] Neumayer, E., Weak versus Strong Sustainability: Exploring the Limits of Two Opposing Paradigms, Vol. 2, Edward Elgar: Massachusetts, 2003.

[15] ADVANCE, Sustainable Value of European Industry: A Value-Based Analysis of the Environmental Performance of European Manufacturing Companies (full version), The Advance Project, available at: www.advance-project.org, 2006.

[16] Figge, F. \& Hahn, T., Sustainable value in the minerals industry. Sustainable Development Indicators in the Minerals Industry, Vol. 1, ed. P.N. Martens, Aachen International Mining Symposia ed., Glückauf: Essen, 2005.

[17] Hahn, T., Liesen, A., Figge, F. \& Barkemeyer, R., Nachhaltig erfolgreich Wirtschaften: Eine Untersuchung der Nachhaltigkeitsleistung deutscher Unternehmen mit dem Sustainable-Value-Ansatz - Langversion (Sustainably Successful? Analysing, Measuring and Managing Corporate Sustainability with the Sustainable Value Approach), available at: www.new-projekt.de, 2007.

[18] Krajnc, D. \& Glavic, P., A model for integrated assessment of sustainable development. Resources, Conservation and Recycling, 43, pp. 189-208, 2005.

[19] Krajnc, D. \& Glavic, P., How to compare companies on relevant dimensions of sustainability. Ecological Economics, 55(4), pp. 551-563, 2005.

[20] Saaty, T.L., Analytical Hierarchy Process: Planning, Priority Setting, Resource Allocation, McGraw-Hill: New York, 1980.

[21] Bechmann, A., Nutzwertanalyse, Bewertungstheorie und Planung, Paul Haupt: Bern, 1978.

[22] Baumgartner, R.J., Sustainability assessment. Einsatz der Fuzzy Logic zur integrierten ökologischen und ökonomischen Bewertung von Dienstleistungen, Produkten und Technologien, Techno-ökonomische Forschung und Praxis, eds U. Bauer, H. Biedermann \& J.W. Wohinz, DUV: Wiesbaden, 2004. 
[23] Baumgartner, R.J., Dealing with uncertainty: integrated sustainability assessment based on fuzzy logic. Sustainable Development and Planning II, Vol. 1, eds A.G. Kungolos, C. Brebbia \& E. Beriatos, WIT Press: Southampton \& Boston, 2005.

[24] Zadeh, L.A., Fuzzy sets. Information and Control, 8, pp. 338-353, 1965.

[25] Mechler, B., Mayer, A., Schlindwein, A. \& Wolke, R., Fuzzy logic. Einführung und Leitfaden zur praktischen Anwendung, Vol. 1, Addison-Wesley: Bonn, 1993.

[26] Bojadziev, G. \& Bojadziev, M., Fuzzy logic for business, finance, and management. Advances in Fuzzy Systems - Applications and Theory, eds L.A. Zadeh, K. Hirota, G. Klir, E. Sanchez, P.Z. Wang \& R. Yager, World Scientific: Singapore, 1997.

[27] Figge, F., Öko-Rating: ökologieorientierte Bewertung von Unternehmen, Springer: Berlin, 2000.

This paper is an extended version of the one presented by the authors at the 1st International Conference on Environmental Economics and Investment Assessment, held on the island of Mykonos in 2006, Volume 98, WIT Transactions on Ecology and the Environment (ISBN: 1-84564-046-2/ Online ISSN: 1743-3541). Edited by K. Aravossis, C.A. Brebbia, E. Kakaras and A.G. Kungolos. 